\title{
Impacts of Rainfall Variability on Potato Productivity in Haramaya District, Eastern Hararge Zone, Ethiopia
}

\author{
Shame Ahmed Adem \\ Department of Agro-Meteorology and Natural Risk Management, Haramaya University, Dire Dawa, Ethiopia \\ Email address: \\ Shamamad360@gmail.com \\ To cite this article: \\ Shame Ahmed Adem. Impacts of Rainfall Variability on Potato Productivity in Haramaya District, Eastern Hararge Zone, Ethiopia. Journal \\ of Chemical, Environmental and Biological Engineering. Vol. 5, No. 1, 2021, pp. 9-22. doi: 10.11648/j.jcebe.20210501.13
}

Received: December 7, 2020; Accepted: December 21, 2020; Published: March 17, 2021

\begin{abstract}
Rainfall variability is one of the most influential climatic factors that determine crop productivity. This study was conducted to analyze rainfall variability and its impact on potato productivity for the period of 2000-2019, and to assess farmer's perception on impacts of climate variability and evaluate their adaptation measures for potato productivity in Haramaya District. Primary data were obtained from randomly selected farmers through questionnaire, key informants interview and field observation. Secondary data on rainfall and potato production were collected from Ethiopia Meteorological agency and Haramaya District Agriculture Office. Purposive sampling was used to select 362 farmers in the district. Proportionate sampling was used to select the sample of farmers in each of the three kebeles (Tiniqe, Tuji Gabisa and Kuro). The data collected were analyzed using Statistical software SPSS. Annual rainfall and potato yield showed decreasing trend from 2000 to 2019. Annual rainfall trends variability was significant and ranged from -25.25 in 2009 to +48.99 in 2007 . Annual Potato yield trends variability was also significant and ranged from -33.14 in 2000 to +60.89 in 2007 . Rainfall variations, crop diseases, pests, and high cost of inputs have been the major challenges facing potato production in the study area. Forty three percent (43\%) of the respondents agreed that rainfall variation was the main cause of decreased potato yields $24 \%$ crop diseases and pests and 15\% high cost of inputs 10\% inadequate improved seed and $8 \%$ soil erosions. From the findings Pearson's $r=0.668$ showed that there was significant impact of rainfall variability trend on potato yields. From the findings, the study recommended that soil and water management practices such as mulching, digging of trenches, water harvesting, crop diversification and use of irrigation during the dry spell as adaptation measures should be applied to cope with rainfall variation.
\end{abstract}

Keywords: Potato, Rainfall Variability, Haramaya, Perception

\section{Introduction}

The global average temperature has increased by $0.78^{\circ} \mathrm{C}$ since the beginning of industrial revolution, and future projections indicate that temperature is likely to increase between $1.5^{\circ} \mathrm{C}$ to $2^{\circ} \mathrm{C}$ until the end of this century. Longterm changes in rainfall and temperature are the most commonly used proxies for climate change. Rainfall in particular is a prominent climatic factor that affects agricultural production through its impact on timing of agricultural operations. "Notwithstanding non-climatic factors, rainfall dictates how land is used and types of crops that are cultivated in a particular area [1]". Rainfall change and its threats to food security and sustainable development are stronger in poorer regions of the world including Eastern
Africa.

Agriculture is backbone of Ethiopia's economy as it accounts for half of Gross Domestic Product (GDP) and 80\% of employment [14] This sector is highly sensitive to climate variability. Thus, the dependence of Ethiopia on climatesensitive agriculture makes its economy extremely vulnerable to the risks associated with climate variability. "Historical evidences suggest that there is a strong relationship between rainfall and GDP of the country [24]". The country has experienced rainfall variability and associated drought that caused food insecurity and famine in many parts of the country in recent decades [2]". The 1984 famine, considered as the worst famine the country experienced during $20^{\text {th }}$ century, happened due to rainfall failure during main rainy season [20]". "The magnitude might differ but similar rainfall 
failure and scarcity have been occurring in recent years in many parts of the country compromising production capacity of the farmers [12]".

The highlands of East Africa are well known for potato production that takes advantage of the two rainy seasons. "The lowlands, however, are subject to erratic rainfall and poor soils [13]". The effect of rainfall variability on potato yields has been felt in Africa and beyond. The average potato yields in sub Sahara Africa have remained stable at between 5-10 tons per hectare "while those in Western Europe are over 30 tons per hectare [10]". Temperature changes triggers changes in other climate elements such as precipitation, wind and pressure systems. For example, increased rainfall in East Africa often causes floods that lead to displacement of people and destruction of properties. "Severe drought has frequently affected sub-Sahara Africa in the recent years [15]". The human suffering that has accompanied these extreme events provides an indication of the vulnerability of Sub Sahara African societies to rainfall variability. "For example, in 1992, 20 million people in the region were in dire need of food relief because of drought; the same scenario was repeated in Zimbabwe, Mozambique, Kenya, Somalia and Ethiopia during the 2000's [9]'”.

In Ethiopia, potato is grown by about 1.2 million smallholder farmers on about 70, 131 ha of land [3]". "Potato plays a pivotal role in improving food security, increasing smallholder farmers' income and reducing poverty [8]". In Haramaya District, "dense population, small farm size, mainly characterizes households declining soil fertility, severe land degradation; fragile ecosystems and recurrent weather-induced shocks such as drought are occurred to the environment as weather events [22]". Smallholder farmers in this region face frequent risks to their potato production such as disease outbreaks, pest damage, wilt incidence, storage problems and occurrence of extreme weather events commonly called frost (Wurchi/Amadey). "The eastern Ethiopian highlands suffer from food production deficits and of high livelihoods vulnerability due to the aforementioned climate change-induced risks [22]". Therefore, the rate of food production has failed to keep pace with the "high rate of population growth resulting in high levels of food insecurity [17]"'.

In Ethiopia, climate variability because of recurrent drought, unreliably rainfall and high temperature are still main climate problems. "Recurrent drought, unreliably rainfall and high temperature are main problems that affect millions of people in the country almost every year [16]". Rainfall variability is the main climatic parameter, which impacts are on crop yields. The impacts of climate variability further aggravated by poverty and population pressures [23].

In the study area based on the varied in environmental conditions and management practices and Day to day extreme events are influencing the population demands requires rising in the agricultural production with available resources. Available resources with stable weather conditions are essential to increase productivity of agriculture. But in the study area there are climatic variables such as erratic rainfall and unbalanced temperature that affect crop yields which results reduction of productivity and crop faller faced. On the other hand an increase of warming decreases the yield of habituated crops variety. Climate variability affects the ability to increase food production as required by the growing population in Haramaya District, creating a need to assess the rainfall variability that affects potato yields. It is not clear how these variations in potato yields are correlated to rainfall variations. The study attempted to determine the impacts of climate variability (rainfall and temperature) on potato productivity and adaptation strategies in the study area.

The general objective of this study was to analyze rainfall variability and its impact on potato productivity in Haramaya District with the following specific objectives:

1. To assess the annual rainfall trends and variability (2000-2019) in Haramaya District.

2. To assess the impact of annual rainfall and temperature variability on potato productivity $(2000-2019)$ in Haramaya District.

3. To assess farmer's perception on impacts of climate variability and evaluate their adaptation measures to climate variability for potato productivity in Haramaya District.

\section{Materials and Methods}

\subsection{Description of the Study Area}

\subsubsection{Location}

This research was carried out in Haramaya District of Eastern Hararghe zone of Oromia Regional State of Ethiopia. It is one of the 18 districts of the zone, and located $520 \mathrm{~km}$ east of Addis Ababa, the capital city of Ethiopia. The district is geographically located at $42^{\circ} 3$ ' longitude, $9^{\circ} 26^{\prime}$ latitude, with its altitude ranging from 1,400 to 2,340 meters above sea level (masl). It is bordered by Kurfa Chale District in the south, by Kersa District to the west, to the north by Dire Dawa City, to the east by Kombolcha District, and by the Harari National Region State to the southeast [17].

\subsubsection{Climate}

The district is part of the Ethiopian highland system, and lies in the semi-arid tropical belt of eastern Ethiopia. It is, therefore, representative of a sub-humid mid-altitude agroclimatic zone. Rainfall is bimodal, and the mean annual rainfall received ranges from 600 to $1,260 \mathrm{~mm}$. The short season (Badheessa), usually starts in March and ends in May, and the long season (Ganna) rainfall occurs between June and September. Relative humidity varies between 60 and $80 \%$. Minimum and maximum annual temperatures range from $9.9^{\circ} \mathrm{C}$ to $24.18^{\circ} \mathrm{C}$ respectively [21] Agro- ecologically the district can be categorized as woinadega (59.3\%) and kola $(40.7 \%)$ [6].

\subsubsection{Land Use and Land Cover}

The district comprises 33 rural and three urban kebeles [7] It has an area of 52,163 ha, out of which 38,407 ha was used 
for farming/cultivation/, forests and bushes cover 825 ha, and 324 ha was used for grazing. In the district mixed croplivestock farming is the dominant production system. Cash crops (khat and vegetable crops), food crops (sorghum and maize) were mostly practiced.

\subsubsection{Population}

The district has an estimated total population of 304,276. Of whom 152,442 (50.1\%) were men and 132,736 and $151,834(49.9 \%)$ were women. About $19 \%(50,032)$ of its population is urban dwellers, which is greater than the zone average of $6.9 \%$. With an estimated area of 550 square kilometers, Haramaya District has an estimated population density of 430.2 people per square kilometer, which is greater than the Zone average of 102.6.[6].

\subsubsection{Livelihood}

Agriculture is the main stay of the districts economy and nearly $90 \%$ of the population directly or indirectly depends on this sector. Mixed farming system was considered as the most common practice across all agro ecological zones, which cash crops (chat and vegetable crops), food crops (sorghum, maize, pulses and other cereals), and livestock production are the main source of livelihoods. Land holding size is small and fragmented and, hence, the average land holding size was found to be $(<0.5)$ ha. Among vegetable crops, potato was the most cultivated and has covered a larger area in this district. Out of 33 rural kebeles, potato is grown in 17 kebeles and it covers a total area of 1532 ha. In the District, 7591 households were involved in the production of potato in 2014/015 production season. In the study area, potato is cultivated twice a year. The first round starts in September and ends in January where vegetables and root crops are produced using irrigation, whereas the second round starts in February and ends in June where horticultural production is practiced using irrigation and rainfall [7].

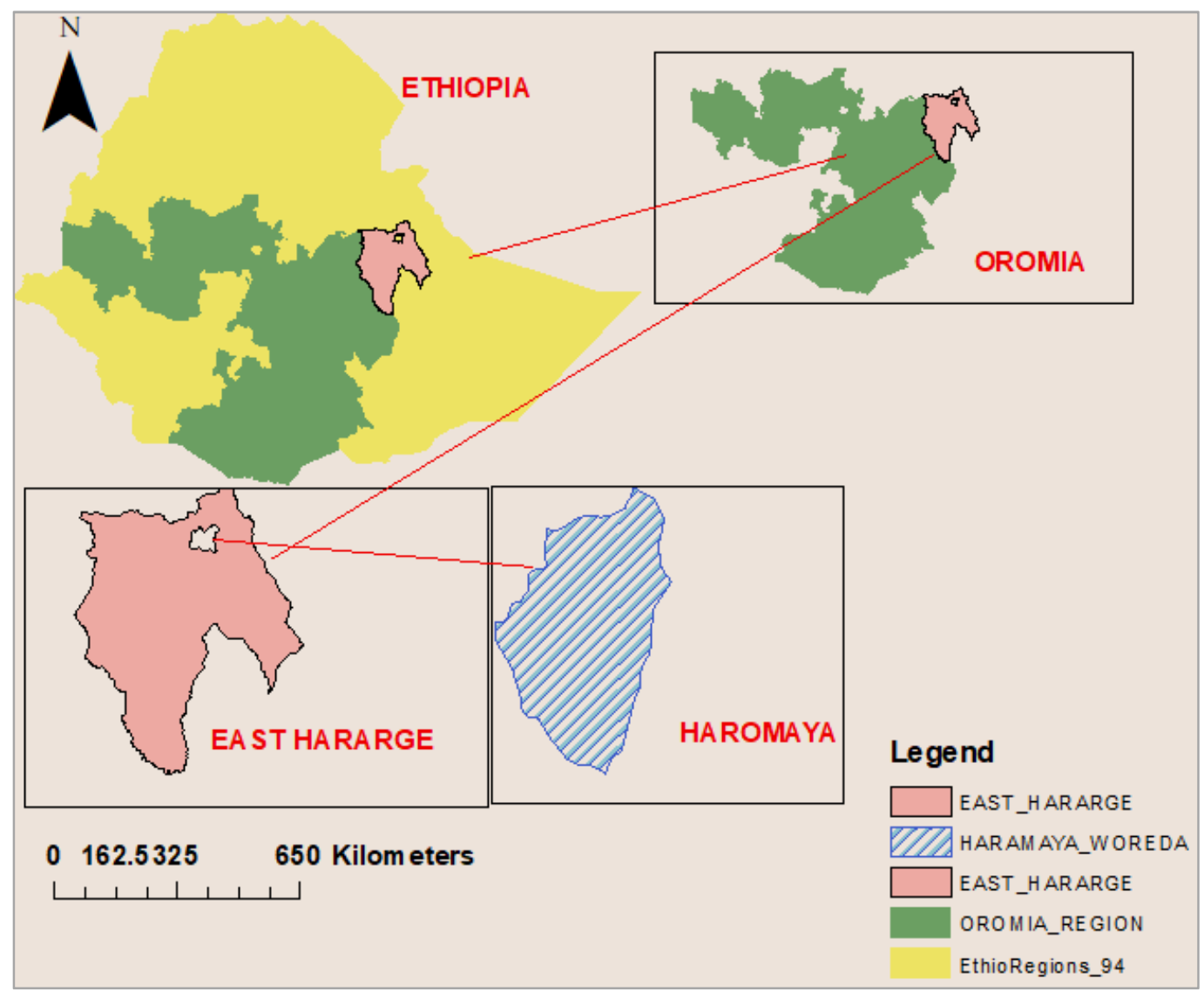

Figure 1. Map of the Study Area.

\subsection{Sampling Procedure and Sample Size}

Out of potato producing kebeles in the study area, three kebeles (TujiGabisa, Tinke and Kuro) were selected purposively based on the maximum area coverage under potato crop production. "The formula was used to determine sample size by [26]". From the total 3876 household live in this three kebeles 362 farmers were selected, because of similar characters in their livelihoods, sample size will be determined by simple sampling formula expressed and calculated as follows:

$$
\mathrm{n}=\frac{\mathrm{N}}{1+N(e 2)} \text { Yamane (1967) }
$$

Where, $n=$ required sample size

$\mathrm{N}=$ total house hold in three kebeles

$\mathrm{e}=$ expectation error

$\mathrm{n}=3876 / 1+3876(0.05)^{2}$ 


\section{$\mathrm{n}=362$}

All potato farmers were listed and used as sample frame unit in each kebelles, that is Ni. Lastly, 362 sample farmers were selected randomly based on potential potato producers.

$\mathrm{n}=\frac{\mathrm{Ni} * \mathrm{n}}{N}$ Tuji Gabisa kebele $(\mathrm{Ni})=1574$ Tinike kebele

$(\mathrm{Ni})=1060$ Kuro kebele $(\mathrm{Ni})=1242$

$\mathrm{n}=$ total sample size, $\mathrm{N}=\mathrm{TOTAL} \mathrm{HHH}$ in each three

kebelles, $\mathrm{Ni}=$ each kebelles $\mathrm{HHH}$ frame unit

$\mathrm{n}=147$ Tuji Gabisa kebele

$\mathrm{n}=99$ Tinike kebele

$\mathrm{n}=116$ Kuro kebele

\subsection{Data Types, Source and Methods of Data Collection}

\subsubsection{Primary Data}

Primary data such as, perception of respondents on climate change, socio status and economic characteristics background were collected from randomly selected farmers in the area through questionnaires, individual interviews and group discussions. Questionnaires containing structured questions and key informant interviews was conducted with selected individuals who have better understanding of the relationship between agricultural production and rainfall variability. Interviews and questionnaires were administered with the local language of the study area. A Focus Group Discussions (FGDs) was also organized with model farmers and Development Agents (DAs) in three kebelles, Tuji Gabisa, Tinke and Kuro. For the purpose of data analysis, descriptive (intervals, percentage, and graphs) were used.

\subsubsection{Secondary Data}

Daily, monthly, seasonal and annual rainfall and temperature data of 2000-2019 was collected from National Meteorological Service Agency (NMSA) of Ethiopia through Haramaya station. Annual potato yield data between (2000 and 2019) was from the District Agricultural Office. The data collected was from the annual data recording found at the Haramaya agriculture Office. The recordings captured consisted the number of planted land in (ha) within growing season excluding irrigation and the actual yields realized in the year.

\subsection{Data Analysis}

\subsubsection{Rainfall, Temperature and Potato Yield Data Analysis}

In this study Micro soft excel, stat excel, statistical software SPSS and INSTAT plus software tools were used summarizing the daily rainfall and temperature data set into monthly, seasonal and annual totals for (2000-2019) years to analyze the onset and end date of rainfalls, dry spell and length of growing period (LGP) in Haramaya District. And also annual potato yield data between (2000-2019) years was computed with Simple line graph and the trend line drawn to determine the significance of the trend. Trend analysis was done to determine the impact of rainfall and temperature on potato yields in Haramaya District. Monthly, seasonal and annual variability indices to rainfalls, temperature and potato yield data was computed using the coefficient of variation
(CV) equation (2) as follows

$$
C V=\frac{S D}{\overline{\mathrm{X}}} * 100
$$

Where, $\mathrm{CV}$, is coefficient of variation, $\mathrm{SD}$, is standard deviation while $\overline{\mathrm{X}}$ is the long-term mean. According to Hare (1983), CV percentage values are classified as follows: $<20 \%$ as less variable, $20-30 \%$ as moderately variable, and $>30 \%$ as highly variable. On the other hand, the timing, variability and quantity of annual rainfall are important factors concerning climate and cultivation.

\subsubsection{Rainfall and Temperature Trend Analysis}

Monthly, seasonal and annual rainfall and temperature data between (2000-2019) period was investigated for trend analysis using non-parametric Mann-Kendall test. Linear trends analysis was also carried out using linear regression procedure to detect the trend on monthly, seasonal and annual basis. First, (MK) is a non-parametric test and does not require the data to be normally distributed. Second, the test has low sensitivity to abrupt breaks due to in homogeneous time series. Each data value is likened to all subsequent data values. If a data value from a later period is higher than a data value from an earlier time, the statistic $S$ is increased by one. On the other hand, if the data value from the later period is lower than a data value sampled earlier, one decreases $S$. The net result of all such increments and decrements is one that determines the final value of $S$. The Mann-Kendall $Z$ Statistic was mathematically computed as follows:

$$
\begin{gathered}
\text { Zs }=\sum_{i=1}^{n-1} \sum_{\mathrm{j}=\mathrm{i}+1}^{\mathrm{n}} \operatorname{sign}(\mathrm{Tj}-\mathrm{Ti})- \\
\text { Sign }\left(\mathrm{T}_{\mathrm{j}}-\mathrm{T}_{\mathrm{i}}\right)_{2}=\left\{\begin{array}{c}
1 \text { if } T j-T i>0 \\
0 \text { if } T j-T i=0 \\
-1 \text { if } T j-T i<0
\end{array}\right.
\end{gathered}
$$

Where $\mathrm{T} j$ and $\mathrm{Ti}$ are the annual values in years $\mathrm{j}$ and $\mathrm{i}, \mathrm{j}>\mathrm{i}$ respectively. A positive value of $\mathrm{Z}$ indicates an increasing trend whereas a negative value indicates a declining trend in the data. At certain probability level $\mathrm{H} 0$ is rejected in favor of $\mathrm{H} 1$ if the absolute value of $Z$ equals or exceeds a specified value $Z \alpha / 2$, where $Z \alpha / 2$ is the smallest $Z$ which has the probability less than $\alpha / 2$ to appear in case of no trend. The standard test statistic Zs was calculated as follows:

$$
\mathrm{Z}_{\mathrm{s}}=\left\{\begin{array}{c}
\frac{s-1}{\sigma} \text { for } s>0 \\
0 \text { for } s=0 \\
\frac{\mathrm{s}+1}{\sigma} \text { for } s<0
\end{array}\right.
$$

The test statistic Zs was used as a measure of significance of the trend. In fact, this test statistic was used to test the null hypothesis. Ho, If $|Z s|$ is greater than $Z \alpha / 2$, where $\alpha$ represents the chosen significance level then the null hypothesis is rejected implying that the trend is significant.

Correlation and regression analysis were used to establish the relationship and impact of rainfall and temperature on 
potato yields in the study area. The regression equation for the study has been in the form of:

$$
\mathrm{Y}=\mathrm{a}+\mathrm{b}_{1} \mathrm{x}_{1}+\mathrm{b}_{2} \mathrm{x}_{2}+\mathrm{b}_{3} \mathrm{x}_{3} \ldots \ldots \ldots \ldots \ldots \ldots \mathrm{b}_{\mathrm{n}} \mathrm{x}_{\mathrm{n}}+\mathrm{e}
$$

where; $\mathrm{Y}=$ the value of the dependent variable (potato yields in $\mathrm{qt}$ or $\mathrm{qt} / \mathrm{ha}) ; \mathrm{a}=\mathrm{Y}$ intercept and $\mathrm{b}_{1}, \mathrm{~b}_{2}, \mathrm{~b}_{3}$, $b_{4}, \ldots \ldots \ldots b_{n}=$ regression coefficients, $x_{1}, x_{2}, x_{3}, x_{4}, \ldots \ldots \ldots$. $\mathrm{x}_{\mathrm{n}}=$ The independent variables such as annual rainfall total and, $\mathrm{e}=$ the error of estimate or residuals of the regression. The formula for (r) is as follows:

Formula for computing correlation

$$
\mathrm{r}=\frac{\sum \mathrm{XY}}{\sqrt{\left(\sum \mathrm{X}^{2}\right)\left(\sum \mathrm{Y}^{2}\right)}}
$$

Pearson Correlation coefficient (r) was used to establish the relationship between potato yield with rainfall amount Value of $r$ ranges between -1 to +1 , a correlation coefficient close to +1 indicates a strong positive correlation, a correlation coefficient close to -1 indicates a strong negative correlation and a correlation coefficient of 0 indicates no correlation. F-distribution test have been employed for testing all the coefficients in a regression model. If P-value of $\mathrm{F}$ exceeds 0.05 (confidence level) the explanatory variable does not predict response variable. The data were analyzed using statistical software SPSS. Frequencies, percentages and proportions were used in interpreting the respondents' perception of issues raised in the questionnaire. The data were presented using tables, line and bar graphs, pie charts and proportional circles.

\section{Results and Discussions}

\subsection{Rainfall Characteristics}

\subsubsection{Onset, End Date and Length of Growing Season}

AS on Figure 2. Show the existing variability of the onset date, end date and LGS at Haramaya District were as on (Figure 2) The up pending curve shows the high variability of onset date of rainfall as compared to the rest rainfall features. The lower and upper quartiles of the timing of onset of rainfall are in a range of 80 (April 11)-137 (May 17) DOY. Therefore, planting earlier than 11 April is possible in Haramaya District once in twenty years' time. On the other hand, planting earlier than 17 May (137 DOY) is possible. Accordingly, the rainy season could not extend beyond the end of the third dekad of September (301 DOY) at Haramaya District. The relatively steep curve of the cumulative probability graph for end date of the season Figure 6 indicates the predictable nature of cessation of the rainfall in the area. The other vital rainfall feature to be considered from crop production point of view is the variation in length of growing season. The probability that the LGS will be shorter than 121 days is $85 \%$ while the probability that it will be longer than 221 days is $30 \%$ as shown on (Figure 3 ). The mean LGS in Haramaya District is 174 days. The LGS variability at Haramaya District is mainly attributed to high variability in onset of rain as the rainfall end date variability is less. Therefore, the early onset associated with high amount rainfall and late onset with less rainfall amount.

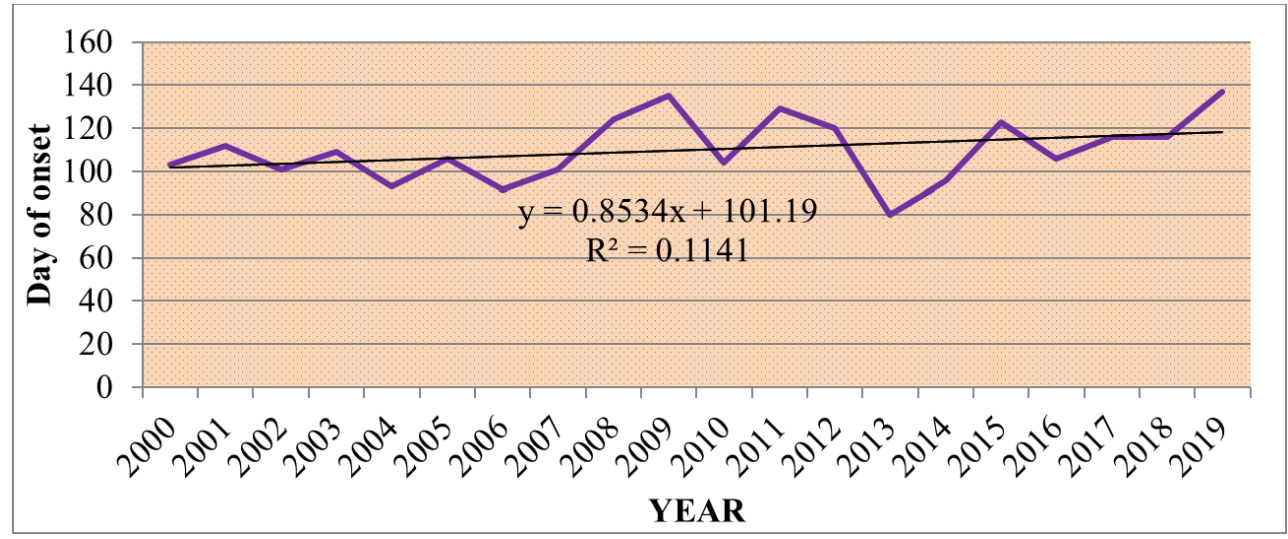

Figure 2. Day of onset of rainy season at Haramaya stations, considered start of rain is first April.

\subsubsection{Probability of Dry Spell Length}

Probabilities of dry spell lengths computed during potato growth periods in the study area are crucial to determine seedling establishment and potential potato growth performance at different growth stages. The occurrence of higher probability dry spell lengths at critical stages of potato growth were damaging specially at flowering and seed filling stages. The probability of dry spell lengths greater than 5,7 , 10 and 15 days starting from January were computed for the study area. The probability of dry spell length of 5 days was found to be $85 \%$ during 121 DOY (1st decade of june), then it declined to below $30 \%$ by 221 DOY (3rd decade of July)
(Figure 3). Beginning from 221 DOY, the probability that the area faced dry spell length of 5 days had been increased up to $100 \%$ by 301 DOY (3rd decade of September). Probability of dry spell lengths of 7 days or a week has been reached about $10 \%$ in July. However, the probability of the occurrences of 10 days and 15 days were fall below $5 \%$ during the main rainy season of the area, JJAS. This is the critical time for potato growing period. Thus, the potato yields in the area might be influenced due to the high occurrences of the dry spell lengths of 5 days than any other dry spell lengths occurrences. "The impacts of rainfall on crop production in Ethiopia are closely related to its variability and occurrence 
of dry/wet spells during the crop growing periods. However, and varieties of crops cultivated [5]". the effect of the rainfall variability on crop varies with types

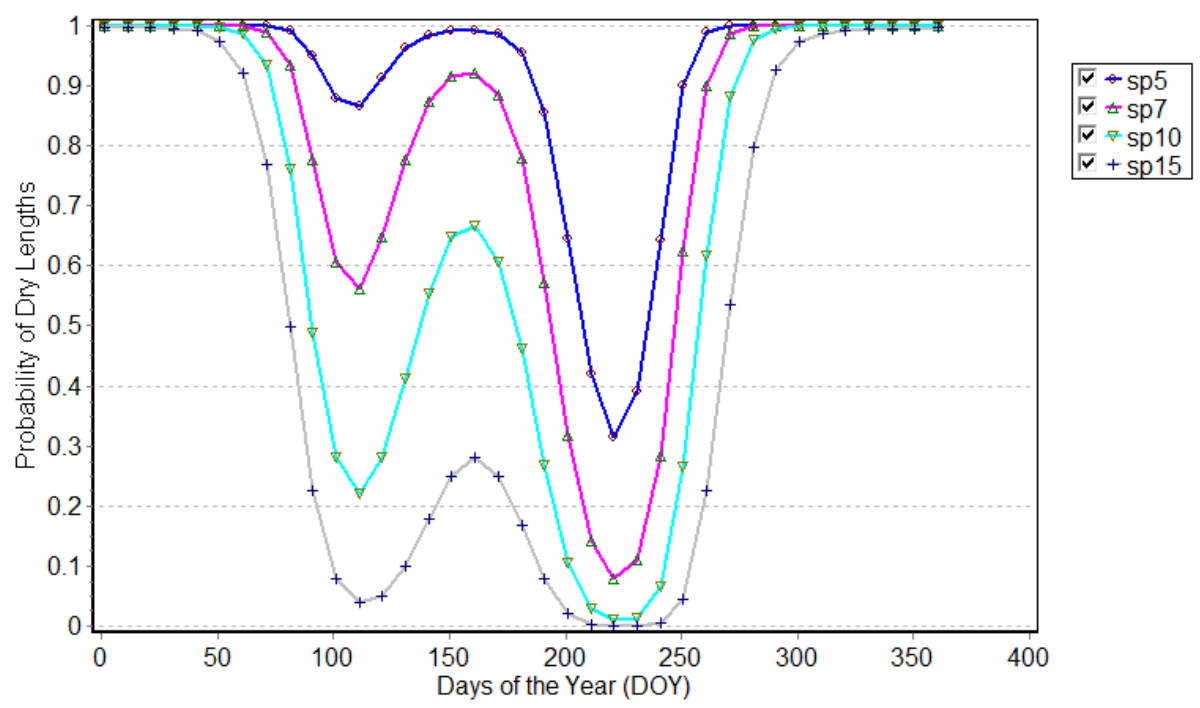

Figure 3. Probability of dry spells longer than 5, 7, 10 and 15 days at Haramaya District starting from January first.

The result in Table 1 revealed that, the main rainy seoson rainfall starts on April 20 (80 DOY) at Haramaya weather station with CV of $13.6 \%$. The lower and upper quartile of the onset date was 101 DOY (11th April) and DOY 122 (1st June) and varies between 110 DOY (minimum) and 137DOY (maximum). This indicates that we can plant potato seed before the onset of the season was earlier than June 1 and the earliest onset date of the main rainy season at Haramaya station was 80 DOY (April 20) while the latest date was 137 DOY (June 1). Late onset is the least preferred situation, obviously because it shortens the available length of Annual potato growing period. Onset date has less standard deviation as compared to length of growing period (LGP), but higher than cessation dates shown in (Table 1). The higher standard deviation of the onset date of the seasons indicates that patterns could not be easily understood and consequently decisions relating to potato planting will be made under high uncertainty.

Rainfall end date analysis showed that the annual rainfall was ceased on 279 DOY (9th October) with CV of $3.2 \%$ shown in (Table 1). The upper quartile, lower quartile, minimum and maximum for the cessation date were 279 DOY (9th October), 313 DOY (13th November), 279 DOY and 285.75 DOY respectively. Upper and lower quartile indicates that the chance of rain to end before 285.5 DOY (10th November). The earliest date of cessation of the annual rainfall was on DOY 279 (9th October) while the latest date was DOY 313 (15th November). However, the rain cessation showed less variability as compared $\mathrm{CV}$ of onset date and cessation date at $3.2 \%$ lower rate than that of $13.6 \%$. Additionally, the Length of growing period for potato production ranged from 144-221 days with CV of $11.6 \%$ and upper Quartile and lower Quartile were 180.25 and 157.75 respectively. We can expect that this range was important and potential LGP for potato yields in the study area. The LGP showed a high variability compared to onset date and cessation date in the study area. It showed that the LGP in the study area was variable which needs more attention for scheduling of agricultural production, crop management practices, farm inputs, select crop that is matching with this growing period, and early maturing variety for sustainable crop production.

Table 1. Descriptive statistics of important rainfall features for Haramaya stations.

\begin{tabular}{llllllll}
\hline Seasonal Rainfall features & Minimum & Lower Quartile & Mean & Upper Quartile & Maximum & SD ( \pm ) & CV (\%) \\
\hline Onset date (DOY) & 80 & 101 & 110.15 & 122.25 & 137 & 14.946 \\
End date (DOY) & 279 & 279 & 284.8 & 285.75 & 313 & 8.9947 & $3.6 \%$ \\
LGP & 144 & 157.75 & 174.65 & 180.25 & 221 & 157.75 & $11.6 \%$ \\
\hline
\end{tabular}

\subsubsection{Analysis of Rainfall Amount, Rainy Days and Mann-Kendall trend Test}

The mean annual rainfall was $691.92 \mathrm{~mm}$ in the study period, with a standard deviation and coefficient of variation $258.52 \mathrm{~mm}$ and 0.39 , respectively. In table 2 the mean annual rainfall total of Haramaya district also varies temporally extended from 291 to $1104.2 \mathrm{~mm}$. Similarly, the mean Seasonal Rainfall total mean was analyzed and summarized in table 2, which is lowest amount of mean rainfall, occurs during the Bega season, and the highest amount of mean rainfall occurs during the Kiremt season. The mean seasonal rainfall during Bega varies from 11.8 to $205.6 \mathrm{~mm}$. This indicates Rainfall increases from the Bega season to the Belg season every year. During the Belg season, the mean rainfall varies from 110.1 to $570.7 \mathrm{~mm}$. the highest amount of mean seasonal rainfall occurs during Kiremt, and the amount of rainfall varies from 180.9 to $566 \mathrm{~mm}$. After Kiremt, rainfall was decreased to its lowest amount as the seasonal trend of rainfall shown in (Table 2) there was a decreasing trend 
during Kiremt and Bega, Contrary in the belg season it shows an increasing trend. The decreasing trend of Bega and kiremt rainfall is statistically insignificant. Annual Rainfall Trend analysis was also performed whether there was trends in the data. The mean annual rainfall of the meteorological data varies from 291 to $1104.2 \mathrm{~mm}$ recorded. Furthermore, it can be noted that the fact that the CV values shown in (Table 2) was so high is an indication of the rainfall being highly variable and the lower the coefficient of variation of the rainfall amount in any year indicates that the lower variability of rainfall. In addition, The Number of rainy day, which recorded rainfall amount, is $0.1 \mathrm{~mm}$ is a threshold value, $1 \mathrm{~mm}$ was used to determine wet and dry days [18]. A day is considered rainy if it accumulates $1 \mathrm{~mm}$ or more rainfall and if it is less than $1 \mathrm{~mm}$ its true for dry day. Based on this definition. The number of annual rainy days observed in the study area varies from 57 days to 187 days with mean 107 days, minimum and maximum 57 and 187 rainy days respectively. Based on the Mankendall's trend test, both the positive and negative trends, however, were not statistically significant at 5\% probability level. Even though, the number of rainy days shows an increasing trend shown in table 2 by Mann-Kendall trend test the amount of mean annual and seasonal rainfall were decreasing.

Table 2. Descriptive statistics of annual and seasonal Rainfall and Mann-Kendall (MK) trend test at significance level of $\alpha=0.05$ at haramaya district (20002019).

\begin{tabular}{|c|c|c|c|c|c|c|c|c|}
\hline Rainfall Total (mm) & Min & Max & Mean & SD & $\mathrm{CV}$ & (MK) test & Trend & Significance \\
\hline$B e g a(\mathrm{ONDJ})$ & 11.8 & 205.6 & 72.44 & 69.78 & 0.96 & -0.43 & Decrease & Insignificant \\
\hline Belg (FMAM) & 110.1 & 570.7 & 110.1 & 105.46 & 0.95 & 1.14 & Increase & insignificant \\
\hline Kiremt (JJAS) & 180.9 & 566 & 399.43 & 170.790 & 0.42 & -1.48 & Decrease & Insignificant \\
\hline Rainy Days & 57 & 187 & 107 & 37.76 & 0.35 & 0.39 & Increase & insignificant \\
\hline
\end{tabular}

FMAM=February, March, April and May, JJAS=June, July, August and September, ONDJ=October, November, December and January $\downarrow$ Decreasing trend $\uparrow$ increasing trend

\subsection{Trends of Rainfall}

\subsubsection{Trends of Annual Rainfall}

The data from the National Metrological Agency (NMA) shows the yearly Annul rainfall decreased over time. The amount of rainfall received has shown continual reduction from year to year, creating more scarcity of precipitation over years. The results in Figures 4 and 5 show that annual and rainy seasonal rainfall amount has decreased between 2000 and 2019 in Haramaya District as shown by the trend line. Peaks are noticed in 2006 and 2013 on Figure 4 while dips are noticed in 2002, 2004, 2009 and 2015. The peak in 2006, 2013 and 2016 is because of favorable rainfall during the long rain season in that year. The dips in 2002, 2004, 2009 and 2015 are because of unfavorable rainfall. Annual rainfall trend shows a decreasing trends where $\mathrm{R}^{2}=0.177$ shows that strength of the line is weak. The findings supports the argument that, "Year to year agriculture is extremely vulnerable to climate variability [25]". Higher temperature and rainfall decreasing eventually reduces yields of crop that "rain fail start late and end earlier than the usual causing erratic rainfall that reduced the yield of potato [4]".

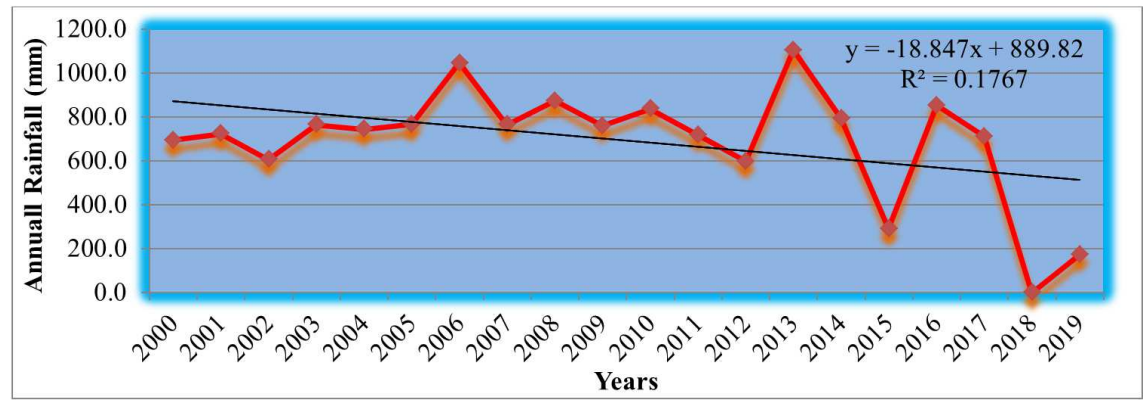

Figure 4. Annual Rainfall Data Trend for Years 2000 - 2019.

\subsubsection{Trends of Seasonal Rainfall}

The results in Figure 5 show a decreasing long seasonal rainfall trend between 2000 and 2019. Yearly seasonal rainfalls were dynamics in the study area. Because of variation of seasonal rainfall. The trend line in the Figure 5 shows that rainfalls during the long rain season were decreased between 2000 and 2019 in Haramaya districts. Peaks are noticed in 2006, 2011 and 2013 while dips are noticed in 2002, 2004, 2009, and 2015. The peaks are as a result of high rainfall in the season while the dips are as a result of low rainfall in the season. $\mathrm{R} 2=0.1234$ shows that the strength of the line is weak. Rainfall variability from season to season greatly affects soil water availability to crops, and thus poses crop production risks. "An overall trends of higher rainfall to correlate with higher yield and lower yield variability in the Amara region [23]". The JJA season minimum and maximum temperature also showed remarkable temporal variability whereas the steady increase in the maximum temperature from 2000 to 2019 showed evidence of warming or dryness. Rising temperatures could also indicate the effect of reduced rainfall (water availability) 
due to increased evaporative water loss and ultimately reduced potato productivity.

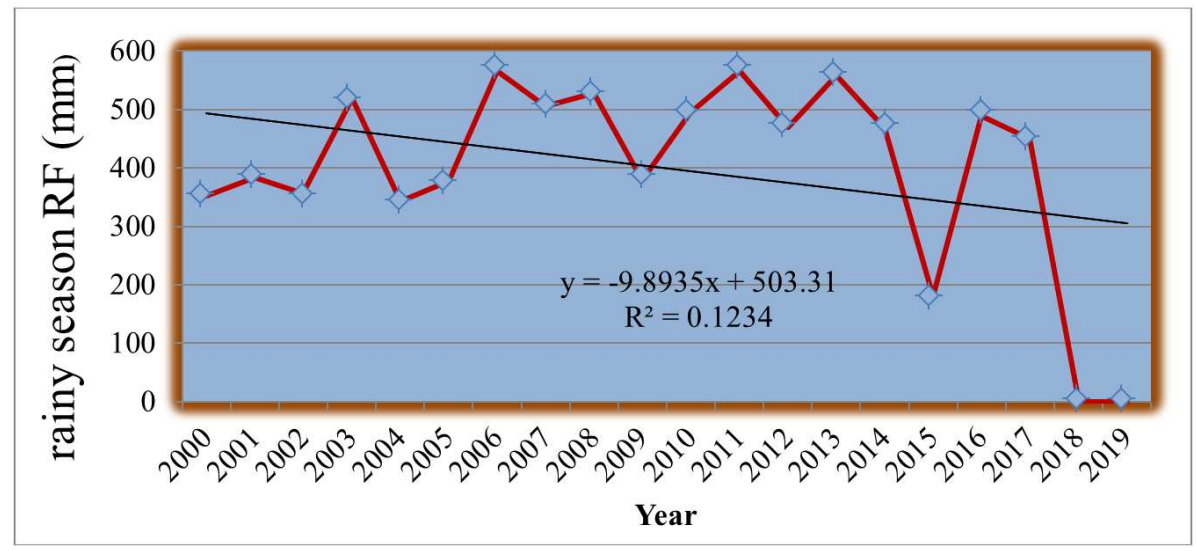

Figure 5. Seasonal Rainfall Data Trend for Years 2000 - 2019.

\subsubsection{Monthly Rainfall Trend Analysis}

In east, Hararghe Zone's rainfall condition shows high spatial and temporal variability. The results of the linear trend analysis for the period of the study (2000-2019) at different seasons clearly demonstrate a general tendency of decreasing in monthly rainfall shown in (figure 6). Rainfall is one of the key indicator and element of climate variability over crop yields. So, changes by rainfall variations have adverse influence on potato yields. In the study area it experienced the long rainy season, which starts around July and runs through to October, while the short rainy season runs from
March to June. As indicated in figure 6, the maximum rainfall peak up in the first month of main rainy season is july and low rainfall amount appeared in September during the study period. On figure 6 , the trend line clearly indicated decline pattern in rainfall amount. The declining of September rain could be the main cause for weakening of rainy season rainfall amount. Several other studies showed that declining trends in rainfall, particularly in the major rainy seasons, have substantiated the existence of a strong link between a downward trend in rainfall as a result of rainfall variability in the study area.

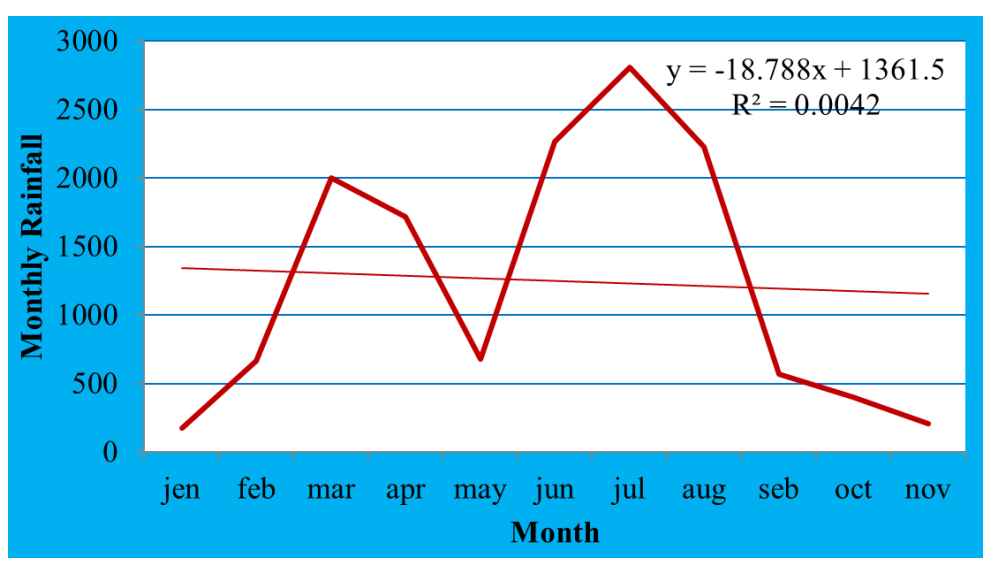

Figure 6. Monthly Rainfall Trend Analysis over (2000-2019).

\subsubsection{Annual Rainfall Variability}

Rainfall variability was computed using rainfall variability index. Annual rainfall variability ranges from +20.614 in 2013 to -34.596 in 2018 as shown in Table 3. Therefore, Rainfall variability is significant in Annual Rainfall trend Shown in Table 3.

Table 3. Annual Rainfall Variability.

\begin{tabular}{|c|c|c|c|c|c|c|c|c|c|c|}
\hline Year & 2000 & 2001 & 2002 & 2003 & 2004 & 2005 & 2006 & 2007 & 2008 & 2009 \\
\hline Annual rainfall (mm) & 695.7 & 724.1 & 607.1 & 766.1 & 744.9 & 767.3 & 1047.4 & 766.2 & 874.4 & 759.7 \\
\hline Annual rainfall variation mean $=691.92$ & 0.189 & 1.61 & -4.24 & 3.71 & 2.65 & 3.77 & 17.77 & 3.714 & 9.124 & 3.39 \\
\hline
\end{tabular}

Table 3. Continued.

\begin{tabular}{|c|c|c|c|c|c|c|c|c|c|c|}
\hline Year & 2010 & 2011 & 2012 & 2013 & 2014 & 2015 & 2016 & 2017 & 2018 & 2019 \\
\hline Annual rainfall $(\mathrm{mn}$ & 837.5 & 719.1 & 598.4 & 1104.2 & 794.3 & 291.0 & 854.3 & 711.7 & 0.0 & 175.0 \\
\hline Annual rainfall variation mean $=691.92$ & 7.28 & 1.36 & -4.676 & 20.614 & 5.12 & -20.046 & 8.12 & 0.99 & -34.596 & -25.846 \\
\hline
\end{tabular}




\subsection{Temperature Trends and Variability}

As depicted in graphs below, trends and anomalies of mean annual temperatures (i.e. mean of Maximum and minimum temperature) of Haramaya district (2000- 2019) were presented in Figure 7 and Figure 8 respectively. "Coefficient of variation was used to classify the degree of variability of rainfall/temperature events according to temperature amount with $\mathrm{CV}$ of less than 0.20 is less variable, $\mathrm{CV}$ between 0.20 and 0.30 is moderately variable and CV greater than 0.30 is highly variable [19]". As of the graph in Figures 7 and 8 below, annual rainfall $(\mathrm{CV}=0.39)$, less variability in the mean annual maximum $(\mathrm{CV}=0.026)$ and minimum temperature $(\mathrm{CV}=0.164)$ were observed in the study area and various simple statistical methods were used to assess climate change and potato yield variability. Table 3 . Showed the commonly used climate variables (annual mean maximum temperature, annual mean minimum temperature, and annual rainfall) and potato yield using simple statistical tools. These four variables were formulated from annual data.

Table 4. Climate Variability on Potato Yield in Haramaya district over the 2000 to 2019.

\begin{tabular}{llllll}
\hline \multirow{2}{*}{ Variables } & \multicolumn{2}{l}{ Statistical Tools } & & \\
\cline { 2 - 5 } & Mean & SD & CV & Variance & Correlation with potato yield (R) \\
\hline Annual Rainfall (mm) & 691.92 & 258.52 & 0.39 & 74254.85 & 0.668 \\
Mean Maximum temperature Celsius (C) & 24.62 & 0.65 & 0.026 & 0.43 & -0.643 \\
Mean Minimum temperature Celsius (C) & 10.08 & 1.65 & 0.164 & 2.735 & -0.029 \\
\hline
\end{tabular}

Source: Authors' own calculation based on data collection from variables

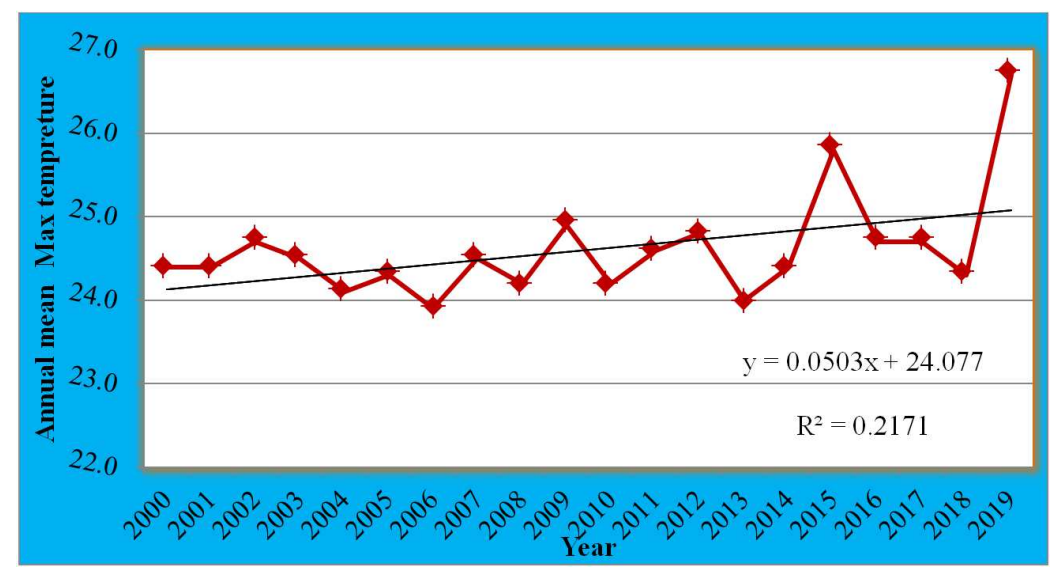

Figure 7. Trends of Annual Mean Maximum Temperatures in Celsius (C) (2000-2019).

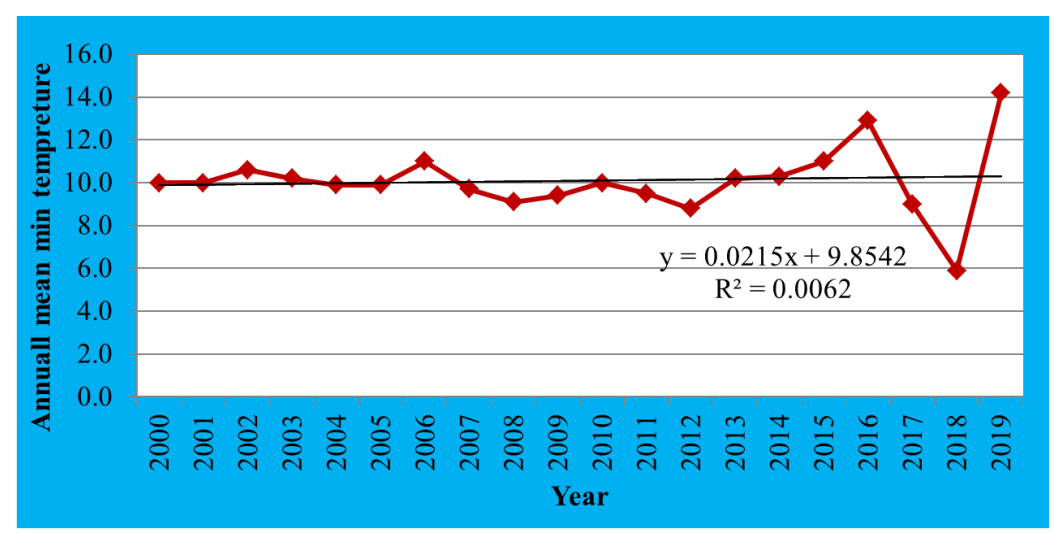

Figure 8. Trends of Annual Mean Minimum Temperatures Celsius (C) (2000-2019)

The relative variability, measured by $\mathrm{CV} 0.39$, is higher for Annual Rainfall (mm), CV 0.026 of Mean Maximum temperature Celsius (C) and $0.164 \mathrm{CV}$ of Mean Minimum temperature Celsius (C) all these provide evidence of changing climate and potato yield in haramaya district over the last 20 years. These aspects of variability become clear where these observations are plotted against time.

\subsection{Trend of Potato Productivity}

\subsubsection{Trend of Annual Potato Yields in Tones}

The study shown on Figure 9. Found that Potato yields have decreased between 2000 and 2019 in Haramaya district as shown by the trend line. The decreasing annual trend is noticed but the yields have varied over the years. $R^{2}=0.0042$ 
shows that the strength of the line is weak. Peaks are noticed in 2006, 2013, and 2016 while dips are noticed in 2002 and 2015. The peaks in 2006, 2013 and 2016 are due to favorable rainfall as shown on Figure 3 on the annual rainfall trend. The dips in 2002 and 2015 are because of the unfavorable rainfall as shown by the dips on figure 3 .

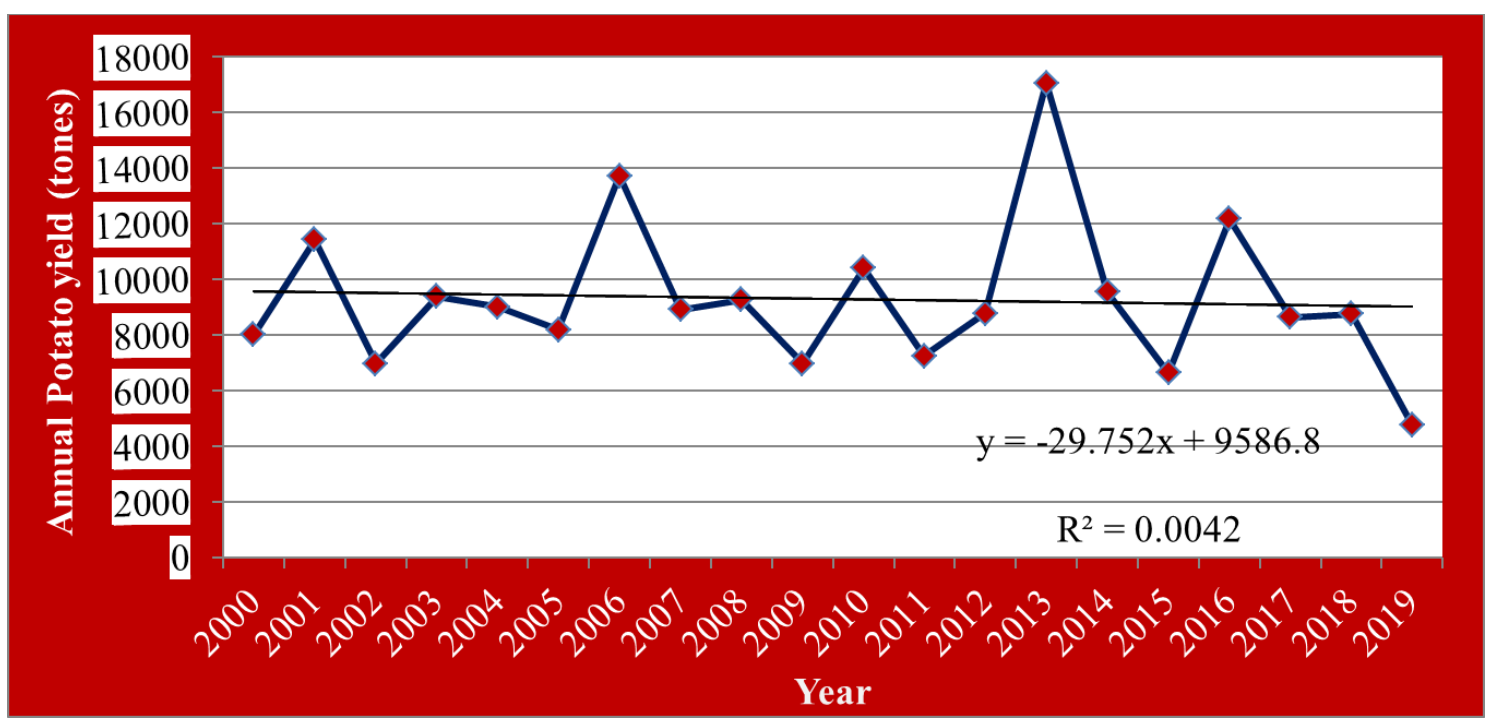

Figure 9. Trend of Annual Potato yields in tons for the years 2000-2019.

\subsubsection{Potato Production Variability}

This analysis of the climate data clearly revealed that there was high variability in Annual rainfall and temperatures were changing over the study area during the period. The two parameters are the most significant weather elements affecting potatoes yields. The study found that temperatures and rainfall were the most significant climatic parameters affecting crop yields because rainfall and temperatures that climatic anomalies like floods, droughts, water shortage and cold waves are most pronounced. Potato production variability was computed using potato variability index. The land under potatoes was not uniform between 2000 and 2019 but ranges between 800 hectares in 2000 to 1430 hectares in 2016. Annual potato yields variability is evident by variations ranging from -116.12 in 2002 to +388.28 in 2013 as shown on Table 5.

Table 5. Annual potato production variability.

\begin{tabular}{|c|c|c|c|c|c|c|c|c|c|c|}
\hline Year & 2000 & 2001 & 2002 & 2003 & 2004 & 2005 & 2006 & 2007 & 2008 & 2009 \\
\hline Annual potato production in (tone) & 8000 & 11400 & 6952 & 9350 & 9000 & 8150 & 13702.5 & 8896 & 9247.5 & 6965 \\
\hline Annual yield variation mean $=9274.4$ & -63.72 & 106.28 & -116.12 & 75.6 & -13.72 & -56.22 & 221.405 & -18.92 & -1.345 & -115.47 \\
\hline
\end{tabular}

Table 5. Continued.

\begin{tabular}{|c|c|c|c|c|c|c|c|c|c|c|}
\hline Year & 2010 & 2011 & 2012 & 2013 & 2014 & 2015 & 2016 & 2017 & 2018 & 2019 \\
\hline Annual potato production in (tone) & 10378.5 & 7231 & 8750 & 17040 & 9522 & 6618 & 12155 & 8624 & 8736 & 4750 \\
\hline Annual yield variation mean $=9274.4$ & 55.205 & -102.17 & -26.22 & 388.28 & 12.38 & 132.82 & 144.03 & -32.52 & -26.92 & -226.22 \\
\hline
\end{tabular}

\subsubsection{Comparative Annual Rainfall, Annual Mean Minimum and Maximum Trend Analysis with Potato Yields Data}

The results in Figure 10 show that variation of rainfall cause variations in potato yields in Haramaya district. As shown by Figure 10, potato yield and rainfall both were decreased in Haramaya between 2000 and 2019. The variation on potato yields with variation of rainfall in the district as the study found supports the arguments, "rainfall determines the type of crop to be grown in different environment as well as the type of agricultural system to be practiced in different parts of the country [11]". The study found that variation and decreased potato yields were caused by variations and decreased rainfall in Haramaya district. These regular occurrences of drought because of erratic rainfall distribution of rainfall during the growing season reduce district's capability for increased crop production. Minimum and Maximum Temperature Trend affect potato productivity in Haramaya district as shown in (Figure 11 illustrate patterns of annual mean minimum and maximum temperature were increased from the long-term historical data of (20000- 2019). The minimum and maximum temperature gradually changed with changing of potato productivity during July to September. On the other hand, a higher minimum and maximum temperature value was observed during July to September shown on (Figure 6). Figure 6 also conveys similar message was observed lower maximum and minimum temperature were on May. The maximum temperature reaches its lowest level in May, but increases again to a maximum in July and start to decline as of September. Therefore, the maximum temperature follows 
an increasing trend of potato productivity in the study area

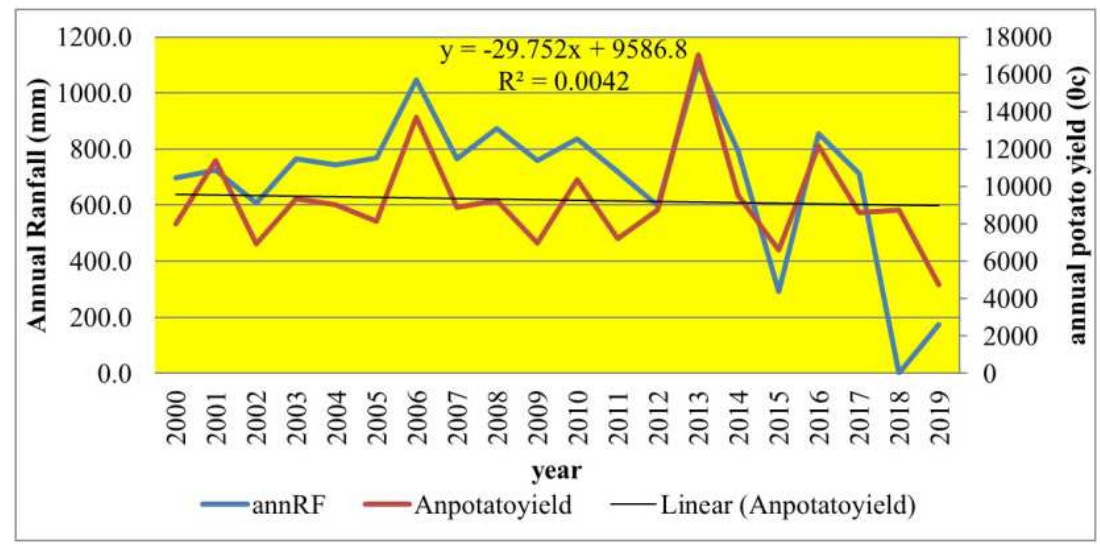

Figure 10. Trend of annual rainfall and Potato yields in tons for the years 2000-2019.

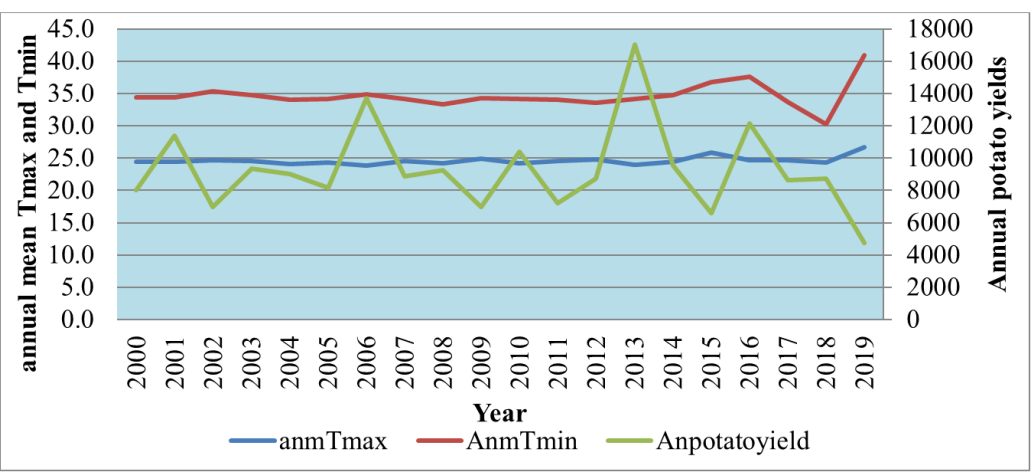

Figure 11. Trend of annual mean Tmax, Tmin and potato yields in tons (2000-2019) years.

\subsection{Correlation of Annual Rainfall Trend and Annual Potato Yields}

The annual rainfall trend and annual potato yields as shown on Table 6 were correlated to determine the significance of rainfall on potato yields. When Pearson's $r$ is close to 1 , this means that there was a strong relationship between the two variables and that change in one variable were strongly correlated with changes in the second variable. When Pearson's $r$ is close to $0 .$. This means that there was a weak relationship between the two variables and that change in one variable were not correlated with changes in the second variable. Consider 20-year annual rainfall variability with potato yield data. Since the data were about twenty years' variables values, it was not possible to make a correlation between each and any of the dependent and independent variables values. However, the degree of association between the two variables can be determined. In this case, it was not clear that whether there was a cause and effect relationship between the two variables and, even if there were one, it would be difficult to specify which the cause was and which the effect was. Hence, the simple linear correlation analysis was applied to measure the degree of linear association between the two variables without specifying the causal relationship. Moreover, correlation was computed as:

$$
\mathrm{r}=\frac{\sum \mathrm{XY}}{\sqrt{\left(\sum \mathrm{X}^{2}\right)\left(\sum \mathrm{Y}^{2}\right)}}=0.668
$$

Because the computed r-value exceeds both tabular rvalues, we conclude that the simple linear correlation coefficient is significantly different from zero at the $1 \%$ probability level. This significant, high r-value indicates that there is strong evidence that the annual rainfall variability and the annual potato yield in each twenty years are highly associated with one another in a linear way.

Testing the significance of the simple linear correlation coefficient by comparing the computed r-value to the tabular r-value with $(n-2)$ degrees of freedom. The simple linear correlation coefficient is declared significant at $\alpha$ level of significance if the absolute value of the computed $r$ is greater than the corresponding tabular $r$ value at the $\alpha$ level of significance. The $\mathrm{r}$ tabular values are:

$\alpha 0.05,18 \mathrm{df}=0.444$

$\alpha 0.01,18 \mathrm{df}=0.561$

Since the R-value of 0.668 is greater than the tabular value at $1 \%$ level, the annual rainfall variability and potato yield are very highly correlated.

From the findings on table 6 . Pearson's $r=0.668$ is close to 1 showing that there was a significant impacts of rainfall amount on potato yield. This means that changes in one variable was strongly correlated with changes in the second variable. A positive Pearson's $r$ means that as one variable increased in value, the second variable also increased in value. Similarly, as one variable decreased in value, the second variable also decreased in value. From the findings, the value 0.001 is less 
than 0.05 meaning that there was a statistically significant correlation between rainfall trend and potato yield.

Table 6. Annual rainfall and Annual potato production trend.

\begin{tabular}{|c|c|c|c|c|c|c|c|c|c|c|}
\hline Year & 2000 & 2001 & 2002 & 2003 & 2004 & 2005 & 2006 & 2007 & 2008 & 2009 \\
\hline Annual rainfall $(\mathrm{mm})(\mathrm{X})$ & 695.7 & 724.1 & 607.1 & 766.1 & 744.9 & 767.3 & 1047.4 & 766.2 & 874.4 & 759.7 \\
\hline Annual potato yields in (tone) (Y) & 8000 & 11400 & 6952 & 9350 & 9000 & 8150 & 13702.5 & 8896 & 9247.5 & 6965 \\
\hline
\end{tabular}

Table 6. Continued.

\begin{tabular}{|c|c|c|c|c|c|c|c|c|c|c|}
\hline Year & 2010 & 2011 & 2012 & 2013 & 2014 & 2015 & 2016 & 2017 & 2018 & 2019 \\
\hline Annual rainfall $(\mathrm{mm})(\mathrm{X})$ & 837.5 & 719.1 & 598.4 & 1104.2 & 794.3 & 291.0 & 854.3 & 711.7 & 307.3 & 737.2 \\
\hline Annual potato yields in (tone) (Y) & 10378.5 & 7231 & 8750 & 17040 & 9522 & 6618 & 12155 & 8624 & 8736 & 4750 \\
\hline
\end{tabular}

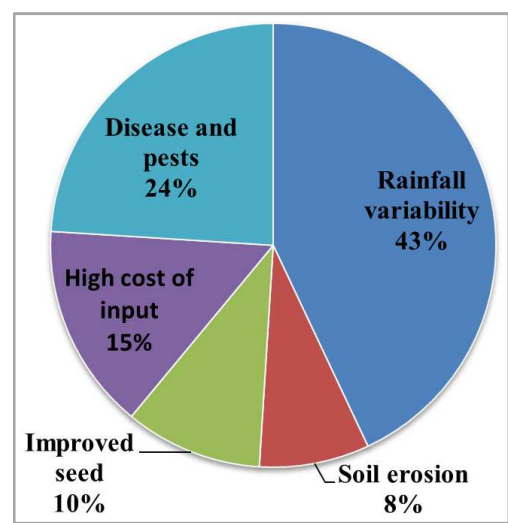

Figure 12. Key challenges facing potato producers.

\subsection{Potato Producer's Perception to Climate Variability}

The farmers were more informed on issues of weather changes. According to the respondents; rainfall variation, diseases and pests are the main challenges to potato farming problems in Haramaya district. As shown in Figure 12. Majority of the respondents $43 \%$ agreed that rainfall variation is the main cause of decreased potato yields in three local sampled kebeles. $24 \%$ diseases and pests, $8 \%$ soil erosion and $15 \%$ high cost of farm inputs while $10 \%$ were inadequate improved seeds cause of decreased potato yields. However, Rainfall was not the only source of water to the potatoes in the study area and therefore means that not only variation of rainfall leads to variations of potato yields rather it was the major cause of decreasing potato yields. Potato diseases such as potato blight have also led to pre-harvest and post-harvest losses in the area and at time increasing the cost of inputs such as cost of fertilizers and pesticides. Farmers were able to adapt easily through crop diversification during times of rainfall variability where they planted such as cabbages and carrots. The farmers also use off season approach to caution themselves from effects of rainfall variability where they plant potato in very small portion of land and leave the rest of the land bare to replenish by other crops and vegetables.

\subsection{Farmers Adaptation Measures to Rainfall Variability for Potato Yields}

\subsubsection{Farmers Adaptation Measures}

From the findings in table 7. crop diversification is the most common adaptation measure practiced in the district followed by timely planting, off season approach and irrigation. Crop diversification $85 \%$ is the most common adaptation measure in TujiGabisa and $40 \%$ irrigation is preferred in Tinike. Timely planting is the most common adaptation measure in three kebeles and least practiced in kuro. Off-season approach is the common adaptation measure in Tujigabisa and the least practiced in Tinike. Irrigation is common in three kebeles.

Table 7. Farmers Adaptation measures.

\begin{tabular}{lllll}
\hline \multirow{2}{*}{ No } & \multirow{2}{*}{ Adaptation Measures } & Name of kebeles & & Total \\
\cline { 3 - 5 } & & Tuji Gabisa & Tinike & Kuro \\
\hline 1 & Crop diversification & 85 & 45 & 40 \\
2 & Timely planting & 39 & 65 & 170 \\
3 & Irrigation & 35 & 40 & 130 \\
4 & Water harvesting & 10 & 15 & 35 \\
5 & No more use of chemical fertilizers & 10 & 25 & 10 \\
\hline
\end{tabular}

Source: own field survey 2019

\subsubsection{Respondents Socio Status}

As the survey, results indicated that from the total respondents of samples HHHs in Table 8. Show that 220 (60.8\%) were literate (have gone through formal education) while 142 (39.2\%) were illiterate (have not gone through formal education). An educated farmer cannot be compared to the one who is uneducated. These educated farmers are in a position to apply for loans and other credit facilities from the various banks in the Country and use their title deeds as security. Education helps farmers in making well-informed decision enabling them increase production and adapt to weather uncertainties. Thus, educated farmers are more receptive to innovations and more likely to adapt to rainfall variability. A high literacy level in the district it is an indication that farmers supplied with the right information have the potential of increasing potato yields in 
Haramaya district.

Table 8. Respondents Background information.

\begin{tabular}{llllll}
\hline No & Background information & Frequency & Percent & Cumulative Percent \\
\hline \multirow{4}{*}{} & & Married & 270 & 74.6 & 74.6 \\
1 & \multirow{3}{*}{ Marital status } & Single & 82 & 22.6 & 22.65 \\
& & Widowed & 10 & 2.8 & 2.8 \\
& & Total & 362 & 100 & 100 \\
& & Farmers & 270 & 74.6 & 74.6 \\
2 & \multirow{3}{*}{ Occupation } & Students & 92 & 25.4 & 25.4 \\
& & Total & 362 & 100 & 100 \\
& & Literate (have formal Education) & 220 & 60.8 & 60.8 \\
3 & Education level & Illiterate (have no formal Education) & 142 & 39.2 & 39.2 \\
& & Total & 362 & 100 & 100 \\
\hline
\end{tabular}

Source: own field survey 2019

The study found that the district has enough human resource needed to improved potato production. Results as in Table 8. Show that majority of the respondents 340 (93.9) were between 23-65 years of age while 22 (6.1) were above 65 years. This is an indication that the farmers are in their productive years. The farmers have the capacity to apply any rainfall adaptation measures that requires their labor, which is available. The high population of farmers who are in their working years is a resource that when well utilized will address the challenges of small land size through intensive farming. The findings support the earlier argument that availability of family labor is vital to farm production especially in terms of the amount of land that can be brought under cultivation. Although from the earlier study, labor alone is not a sufficient factor to potato yield in the district.

Table 9. Respondents Age Group Information.

\begin{tabular}{lllll}
\hline Age Group Information & & Frequency & Percent & Cumulative \% \\
\hline \multirow{3}{*}{ Age group } & 23- 65 years & 340 & 93.9 & 93.9 \\
& Above 65 years & 22 & 6.1 & 100 \\
& TOTAL & 362 & 95.3 & 100 \\
Gender & Male & 345 & 4.7 & 95.3 \\
& Female & 17 & 100 & 100 \\
\hline
\end{tabular}

Source: own field survey 2019

\section{Conclusions}

The main objective of the study was to find out the impact of rainfall variability on potato productivity in Haramaya district. The study found that rainfall amounts have decreased over the years between 2000 and 2019 in Haramaya district. The study also found that there is significant impact of rainfall and temperature on potato productivity in Haramaya district. Rainfall and potato production have varied over the years from 2000 to 2019. Variability of rainfall and temperature leads to variation of potato yield, as rainfall is source of water for potato growth. From the study $r=0.668$ is close to 1 showing that there is a significant impact of rainfall and temperature amount on potato yields. Potato farmers in Haramaya district face several challenges. Rainfall variation, lack of improved seeds, soil erosions, diseases infection, high cost of farm inputs are found to be the major challenges facing potato yields. Improved seeds are either not available or when available they are very expensive and farmers can't afford to buy them. The study reveals that most farmers in the district plant according to traditions and not according to seasonal weather forecast from the Haramaya Meteorological Department. Planting according to tradition leaves farmers vulnerable in case of unforeseen change of onset. From the findings the named challenges; rainfall and temperature variations, lack of improved seeds, pest and diseases if solved the crop still remains economical to plant in Haramaya district. The study has established that farmers have been able to adapt to rainfall variability through irrigation, timely planting, off season approach where they leave a portion of the land bear to replenish during unfavorable rainfall seasons and crop diversification where they plant other crops and vegetables such as cabbages, onions and carrots that matures faster in times of unfavorable rainfall.

From the finding the study recommended that Farmers should plant potato seed varieties that can resist climate variability. Farmers should use mulching to reduce evaporation during low rainfall or negative erratic rainfall and practice crop intensification to increase potato production. Farmers were advised and give attention for scheduling of agricultural production by timely planting crop management practices and farm inputs. They should be encouraged to harvest water and enhance crop diversification to caution them from rainfall variability It should be intensified to utilize the available rains at their different stages of growth such as flowering and maturity. The farmers' field day organized by Farmers Training College should be organized more frequently to enable more farmers to attend and advise them on the appropriate adaptation. 


\section{Acknowledgements}

I owe an immense debt of gratitude to my major Advisor, Abebe Aschalew $(\mathrm{PhD})$ for his encouragement and advice from proposal writing to this Article. I gratefully acknowledge my co-adviser Mengistu Mengesha ( $\mathrm{PhD})$, for his proper guidance, consistent encouragement and inspiration during this work. I am sincerely grateful to the staff of Ethiopian Meteorological Agency, Haramaya station for providing me meteorological and potato yield data.

\section{References}

[1] Arragaw Alemayehu and Woldeamlak Bewket. (2016). Local Spatiotemporal Variability and Trends in Rainfall and Temperature in the Central Highlands of Ethiopia. Geografiska Annaler: Series A, Physical Geography 99 (2), pp. 85-101.

[2] Conway D, Lisa E, Schipper F (2011) Adaptation to climate change in Africa: challenges and opportunities identified from Ethiopia. Global Environ Change 21 (1): 227-237.

[3] CSA.(2017) Ethiopian Population And Housing Census Data Capturing And Processing Implementation Strategy November, 2016.

[4] Dawit and Habtamu. (2011) Climate change adaptations and induced farming livelihoods.

[5] Getaneh, M. 2015 Analysis of Past and Future Intra-Seasonal Rainfall Variability and Its Implications for crop Production in the North Eastern Amhara Region. MSc thesis submitted to Post Graduate Program Directorate, Haramaya University, Ethiopia.

[6] Haramaya Woreda Administrative Office, Annual Administrative Report, East Hararghe, Oromia, Ethiopia, 2018.

[7] Hardo, 2015. Integral Management of Irrigation Water in Intensive Horticultural Systems.

[8] Hirpa, A., Meuwissen, M. P., Tesfaye, A., Lommen, W. J., Lansink, A. O., Tsegaye, A., \& Struik, P. C. (2010). Analysis of seed potato systems in Ethiopia. American Journal of $\begin{array}{llll}\text { Potato } & \text { Research, } & 87 & \text { (6), 537-552. }\end{array}$ https://doi.org/10.1007/s12230-010-9164-1.

[9] IPCC (2007). Climate change 2007: the physical science basis, Contribution of Working Group to the fourth Assessment report of the intergovernmental panel on climate change.

[10] Kaguongo, W., Gildemacher, p., Demo, p., Wagoire, W. Kinyua, P., Andrade, J., Forbes, G., Thiele, G., and fugile, K. (2007). Farmers practices and adoption of improved potato varieties in Kenya and Uganda. Maastridit School of management.

[11] KARI, (2005). Status of potato industry in Kenya. Potato development and transfer of technology report Nairobi. 82.

[12] Kassahun Mamo, M. M. 2013. Crop- livestock inter-linkages and climate change implications for Ethiopia's agriculture. Environment for development, discussion paper series EfD DP 13-14. Pp 32.

[13] Maharjan, Keshav L., Piya, Joshi, Niraj P., Luni. (2011). Effect of climate variables on yield of major food-crops in Nepal -A timeseries analysis Published in: Journal of Contemporary India Studies: Space and Society, Vol. 1, (March 2011): pp. 19-26.

[14] MoARD (Ministry of Agriculture and Rural Development), 2007. Ministry of agriculture and rural development crop development crop variety register. Addis Ababa, Ethiopia, 7: 104.

[15] Muga, M. (2010). Climate Change: A Major Challenge and Revelation for EA Nationals. A journal on resource, reflection and discourse for sustainable development. 32: 201-207.

[16] National Meteorological Agency (NMA) (2007) Climate change national adaptation program of action of Ethiopia. Technical report, United Nations Development Program (UNDP). Addis Ababa, Ethiopia.

[17] Nigussie Dechassa. 2014. Nutritional status of potato (Solanum tuberosum L.) plants and soils in smallholder farms in Ethiopia. Journal of Soil Science and Plant Nutrition. In Press.

[18] NMSA (National Meteorological Services Agency).2001. Report submitted to initial national communication of Ethiopia to the United Nations Framework Convention on Climate Change, Addis Ababa, Ethiopia.

[19] NMSA (National Meteorology Service Agency), 1996. Climatic and agro climatic resources of Ethiopia. National Meteorology Service Agency of Ethiopia, Addis Ababa, 1 (1).

[20] Seleshi, Y. and Zanke, U. (2004). Recent changes in rainfall and rainy days in Ethiopia. International journal of climatology, 24: 973-983.

[21] Sorecha EM (2017) Climate Projection Outlook in Lake Haramaya Watershed, Eastern Ethiopia. Hydrol Current Res 8: 275.

[22] Tesfaye, W., \& Seifu, L. (2016). Climate change perception and choice of adaptation strategies: Empirical evidence from smallholder farmers in east Ethiopia. International Journal of Climate Change Strategies and Management, 8 (2), 253-270. doi: 10.1108/ IJCCSM-01-2014-0017.

[23] Woldeamlake Beweket. 2009. Rainfall variability and crop production in Ethiopia case study in the Amhara region. Department of Geography \& Environmental Studies, Addis Ababa University.

[24] World Bank (2006): Managing climate risk: integrating adaptation into World Bank Group, Global Environment Facility Program, 42 P.

[25] World Bank. 2010. Economics of Adaptation to Climate Change, Ethiopia Country Study Washington, DC. URL http://climatechange.worldbank.org/content/Ethiopia. Accessed on May 25, 2017.

[26] Yamane. (1967) a simplified formula to calculate sample size. 